\title{
An analytical solution to solute transport in continuous arterio-venous hemodiafiltration (CAVHD)
}

\author{
E. Akcahuseyin*, W. A. van Duyl*, M. C. Vos $^{\dagger}$ and H. H. Vincent ${ }^{\dagger}$ \\ *Department of Biomedical Physics and Technology and ${ }^{\dagger}$ Department of Internal \\ Medicine I, Faculty of Medicine, Erasmus University Rotterdam, The Netherlands
}

Received 29 November 1994, accepted 21 February 1995

\begin{abstract}
In conventional intermittent hemodialysis, the overall mass transfer coefficient $\left(\mathrm{K}_{o}\right)$ of a dialyser is mostly calculated at zero ultrafiltration and at relatively high dialysale flow rales. In continuous arteriovenous hemodiafiltration (GAVHD), the dialysate flow rates are low as comparable to the rates of ultrafiltration flows, making the dialysis treatment as slow as possible. Therefore the overall mass transfer coefficient $\left(\mathbf{K}_{d}\right)$ of a CAVHD hemofilter has to be calculated in the presence of ultrafilration. A mathematical model of CAVHD is presented in order to calculate the diffusive mass transfer coefficient $\left(\mathrm{K}_{d}\right)$ for a solute when blood, filtrate and dialysate flow rates and solute concentrations are known. The ultrafiltration volume flux $\left(\mathrm{J}_{v}\right)$ is assumed to vary linearly along the axial direction of the hemofilter. The calculated mass transfer coefficient $\mathbf{K}_{d}$ shows that at high values of dialysate flow and low values of ultrafiltration, the overall mass transfer coefficient $\left(\mathrm{K}_{d l}\right)$ of a CAVHD hemofilter equals mass transfer coefficient $\left(\mathrm{K}_{o}\right)$ of a dialyser in conventional intermittent hemodialysis. Also, the calculated mass transfer coefficient $\mathrm{K}_{d}$ shows no significant differences when the ultrafiltration volume flux is assumed to be constant along the length of the hemofilter if no backfiltration occurs in the hemofilter.
\end{abstract}

Keywords: Continuous arterio-venous hemodiafiltration, mass transfer, mathematical model

Med. Eng. Phys., 1996, Vol. 18, 26-35, January

\section{INTRODUCTION}

Continuous arterio-venous hemofiltration (CAVH) is a form of renal replacement therapy that is used in the intensive care unit. CAVIID is a combination of CAVH and slow dialysis (10$60 \mathrm{ml} / \mathrm{min}$ ). It is characterized by the use of a small surface, highly permeable hemofilter, spontaneous blood flow $(50-350 \mathrm{ml} / \mathrm{min})$ and spontaneous ultrafiltration $(5-20 \mathrm{ml} / \mathrm{min})^{1}$. With CAVH, solute transport occurs by convection and it is limited by the amount of ultrafiltrate production. In CAVH, the patient's blood is pressed into hollow fibers with a highly permeable membrane. As a result of pressure difference across the membrane, fluid is lost from the plasma and it becomes a part of the ultrafiltrate. In contrast to CAVH, in hemodialysis, diffusive transport is the major principle underlying blood purification, especially for the elimination of substances in the low molecular weight range, e.g. of urea and of creatinine. In CAVHD, the solute transport occurs both by convection and by diffusion simul-

Cunespondence to: Dı W. A. van Duyl, Dept of Bionedical Plysics and Technology, Erasmus University Rotterdam, Faculty of Medicine, P.O. Box 1738, 3000 DR Rotterdam, The Netherlands. taneously. In contrast to CAVH, the ultrafiltration is due to the difference between spontaneous physiological blood pressure and the pressure on the dialysate side as a result of flows. Since the CAVHD treatment is a slow and continuous process, the rate of dialysate flow (up to $60 \mathrm{ml} / \mathrm{min}$ ) is lower than it is in conventional hemodialysis $(500 \mathrm{ml} / \mathrm{min})$.

Generally, mathematical analysis of solute transport by combined convection and diffusion in clinical hemodialysis is based on the following equations:

$$
\begin{gathered}
J_{\mathrm{s}}=\gamma J_{\mathrm{v}} C_{\mathrm{m}}+P_{\mathrm{m}}\left(C_{\mathrm{wm}}-C_{\mathrm{md}}\right) \\
J_{\mathrm{v}}=L_{\mathrm{p}}\left(P_{\mathrm{b}}-P_{\mathrm{d}}-P_{\text {onc }}\right)
\end{gathered}
$$

where $J_{\mathrm{s}}$ is local solute mass flux, $C_{\mathrm{wm}}$ and $C_{\mathrm{md}}$ are local solute concentrations in blood and dialysate compartments (see Figure 1) immediately adjacent to the membrane, $\gamma$ is the sieving coefficient, $P_{\mathrm{m}}$ is the permeability representing the reciprocal of resistance to diffusive solute transport within the membrane, $J_{\mathrm{v}}$ is the local ultrafiltration volume flux, $L_{p}$ is the membrane hydraulic permeability, $\left(P_{\mathrm{b}}-P_{\mathrm{d}}-P_{\text {onc }}\right)$ is the local transmembrane (or ultrafiltration) pressure gradient with $P_{\mathrm{b}}, P_{\mathrm{d}}$ and 


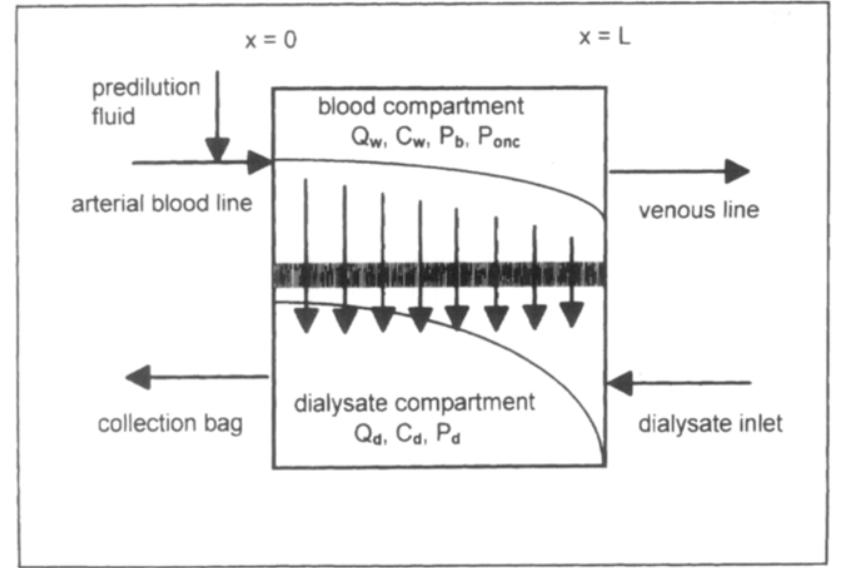

Figure 1 Schematic representation of a CAVHD hemofilter system

$P_{\text {cmic }}$ the local blood, dialysate and oncotic pressure distributions respectively. The $C_{\mathrm{m}}$ in equation (1) is an effective solute concentration describing the convective contribution to the solute flux and given by

$C_{\mathrm{m}}=f_{\mathrm{b}} C_{\mathrm{wm}}+f_{\mathrm{d}} C_{\mathrm{ndd}}$

where $f_{b}$ and $f_{\mathrm{d}}$ are factors describing the weighting of blood and dialysate concentrations. For solutes with sieving coefficient $\gamma=1$ and for small Péclet numbers $\left(\gamma J_{V} / P_{\mathrm{m}} \ll 1\right)$, the weighting factors equal $0.5^{3}$. Therefore the effective concentration $C_{m}$ becomes:

$C_{\mathrm{m}}=\frac{1}{2}\left(C_{\mathrm{wm}}+C_{\mathrm{md}}\right)$.

The actual resistance to the diffusive solute transport from blood into dialysate is a sum of three serial resistances: the blood resistance $R_{b}$ due to the blood boundary layer, the resistance $1 / P_{\mathrm{m}}$ of the membrane and the dialysate resistance $R_{\mathrm{d}}$ due to the dialysate boundary layer, giving the overall diffusive permeability or mass transfer coefficient $\left(K_{d}\right)$ :

$$
\frac{1}{K_{\mathrm{t}}}=R_{\mathrm{w}}+\frac{1}{P_{\mathrm{w}}}+R_{\mathrm{il}} \text {. }
$$

Taking both the concentration boundary layers into account, the interface concentrations $C_{\mathrm{wm}}$ and $C_{\text {mid }}$ have to be written in terms of bulk concentration. The fact that because of the boundary layer forming, the solute concentrations $C_{\mathrm{mm}}$ and $C_{\text {mod }}$ must be corrected in terms of bulk concentrations $\left(C_{\mathrm{w}}\right.$ and $\left.C_{\mathrm{d}}\right)$ on each side of the membrane, necessitates comprehensive knowledge about the resistances $R_{\mathrm{h}}$ and $R_{\mathrm{r}}$. The permeability of the membrane can easily be determined. In clinical practice, however, there is a lack of information about $R_{4}$ and $R_{\mathrm{r}}$. For most solutes the condition $\gamma J_{y} / K_{\mathrm{rl}} \ll 1$ is verified in hemodiafiltration ${ }^{4}$. Therefore equation (1) is practically replaced by

$J_{\mathrm{s}}=J_{\mathrm{v}} \frac{C_{\mathrm{w}}+C_{\mathrm{d}}}{2}+K_{\mathrm{d}}\left(C_{\mathrm{w}}-C_{\mathrm{d}}\right)$

assuming that the $C_{\mathrm{w}}$ and $C_{\mathrm{d}}$ are mixed (average) concentrations. This is also because the average solute concentrations are measured from arterial blood and from dialysate linc connecting to the collection bag (see Figure 1), not directly from the blood bulk inside the fibers and from the dialvsate bulk outside the fibers.

In mathematical analysis of solute transport by combined convection and diffusion, the overall (diffusive) permeability $\left(K_{d}\right)$ is defined as the ratio of the solute flux $\left(J_{0}\right)$ to the solute concentration gradient $\left(\Delta C=C_{\mathrm{w}}-C_{\mathrm{d}}\right)$ when ultrafiltration volume flux $(J)$ vanishes. This corresponds to the overall mass transfer coefficient $\left(K_{s}\right)$ used for conventional hemodialysis. This is due to a lower rate of ultrafiltrate production $(<5 \mathrm{ml} / \mathrm{min})$ than the dialysate flow rate $(500 \mathrm{ml} / \mathrm{min})$. In CAVHD, however, the ultrafiltration flow' rates are no longer negligibly low as compared with the dialysate flow rates. It is then questionable whether the value of $K$, usually obtained at negligible ultrafiltration and at high dialysate flow rates, is valid in the conventional range of ultrafiltrate production (up to $20 \mathrm{ml} / \mathrm{min}$ ) as it is in CAVHD. In his mathematical analysis of combined convection and diffusion, Sigdel $^{6}$ gave expressions for the overall permeability $\left(K_{d}^{\prime}\right)$ with ultrafiltration and $\left(\boldsymbol{K}_{,}\right)$ without ultrafiltration, noting that the ultrafiltration reduces the effective diffusive permeability due to reduction of the concentration gradient $(\Delta C)$, but at the same time adds even more through convection. This expression is valid for the operational limits of conventional hemodialysis $\left(Q_{f} \ll Q_{j} \ll Q_{\mathrm{ji}}\right)$. In their mathematical simulation of CAVHD, Pallone et al. ${ }^{7}$ determined the proper mass transfer coefficient $\left(K_{\mathrm{f}}\right)$ by using curve fitting techniques. Jaffrin et al. ${ }^{4}$ calculated the mass transfer coefficient $\left(K_{1}\right)$ for simultaneous convective and diffusive solute transport in hemodialysers, by making use of $K_{6}$, from the clearance measurements at zero ultrafiltration and curve fitting techniques.

In order to calculate the overall diffusive permeability $\left(K_{\mathrm{r}}\right)$ from clinical data we have developed an analytical mathematical model for CAVHD ${ }^{\circ}$ and used it for clinical data". In that model, the overall diffusive permeability $\left(K_{d}\right)$ (in this paper it is called $\left.\left(K_{\mathrm{a}}\right)\right)$ is expressed as a function of measured blood plasma water, dialysate flow rates $\left(Q_{\mathrm{vi}}, Q_{\mathrm{di}}\right)$ and solute concentrations $\left(C_{w i}, C_{i t s}\right)$ and the rate of ultrafiltrate production $\left(Q_{j}\right)$, assuming that the ultrafiltrate volume flux is constant along the length of the hemofilter. In this paper we developed an analytical mathematical model for CAVHD in order to calculate the overall diffusive permeability from clinical clearance measurements, assuming that the ultrafiltration volume flux varies linearly with the distance along the length of the hemofilter. Within the conventional range of ultrafiltration and dialysate flow rates, the values of calculated $K_{\mathrm{r}} \mathrm{s}$ are compared to the values of $K_{\mathrm{n}}$ and to those of $K$, which are used for conventional hemodialysis.

\section{MATHEMATICAL MODEL}

This mathematical analysis of CAVHD is valid primarily for a hollow fiber dialyser or hemofilter, but with some minor differences also for the parallel plate dialyser. The hemofilter used in this 
study is a bundle of $N$ hollow fibers each with an effective length $(L)$ and radius $(r)$. The surface area $(S)$ of the membrane is equal to the sum of the surfaces of all the fibers. The patient's blood flows via the arterial line into the fibers (blood compartment) to the venous line. The dialysate fluid flows countercurrently to blood flow outside the fibers (dialysate compartment). The blood and dialysate compartments are separated by the membrane. As can be seen from Figure 1, blood from the arterial line enters the hemofilter at $x=0$ (blood inlet) and leaves at $x=L$ (blood oitlet). The dialysate fluid enters the hemofilter at $x=L$ (dialysate inlet) and leaves at $x=0$ (dialysate outlet). The boundary conditions of the blood and dialysate variables are defined as given in Table 1.

\section{Assumptions}

The derivation of the mathematical model is based on the following assumptions:

1. All fibers behave equal, hence the effective surface area of the hemofilter $S=2 N \pi r L$ with $r$ the inner radius and $L$ the filter length.

2. The hydraulic and diffusive permeabilities $\left(L_{\mathrm{p}}\right.$ and $K_{\mathrm{d}}$ ) are constant along the filter length.

3 . The solute concentrations in the blood $\left(C_{\mathrm{s}}\right)$ and in the dialysate $\left(C_{\mathrm{d}}\right)$ are mixing-cup concentrations ${ }^{7}$. This avoids the mathematical complexity of partial differential equations describing the concentration boundary layers and concentration polarization.

4. The flow rates and concentrations are timeindependent during measurements (steadystate).

5. Transmembrane pressure gradient decreases linearly with increasing distance $(x)$.

6. The sieving coefficient is 1 (for small solutes such as urea, creatinine and phosphate). The sieving coefficient is a constant $(0 \leq y \leq 1)$, depending on the relative size of the membrane passing molecules and the membrane pores. It indicates the fraction of the solute that is dragged through the membrane by ultrafiltration.

\section{Pressure-flow relations}

At the beginning of the fibers $(x=0$, blood inlet), the blood pressure $\left(P_{\mathrm{bi}}\right)$ exceeds the sum of the

Table 1 The boundary conditions of CAVHD model variables for countercurrent operation. Explanations and units are given in the appendix

\begin{tabular}{|c|c|c|c|}
\hline Names of variables & $x$ & $x=0$ & $x=L$ \\
\hline $\begin{array}{l}\text { Flow rate of plasma water } \\
\text { Flow rate of dialysate fluid } \\
\text { Solute concentration in plasma water } \\
\text { Solute concentration in dialysate } \\
\text { Concentration of plasma protein } \\
\text { Hydrostatic blood pressure } \\
\text { Dialysate pressure } \\
\text { Oncotic pressure }\end{array}$ & $\begin{array}{l}Q_{2} \\
-Q_{\mathrm{i}} \\
C_{\mathrm{w}} \\
C_{\mathrm{d}} \\
C_{\mathrm{p}} \\
P_{\mathrm{b}} \\
P_{\mathrm{d}} \\
P_{\mathrm{wn}}\end{array}$ & $\begin{array}{l}Q_{\mathrm{wi}} \\
Q_{\mathrm{in}} \\
C_{\mathrm{wi}} \\
C_{\mathrm{cho}} \\
C_{\mathrm{pi}} \\
P_{\mathrm{bi}} \\
P_{\mathrm{di}} \\
P_{\mathrm{inci}}\end{array}$ & 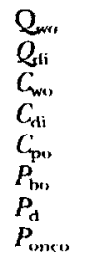 \\
\hline
\end{tabular}

opposing hydrostatic dialysate pressure $\left(P_{\mathrm{d}}\right)$ and oncotic pressure of the plasma proteins $\left(P_{1 m a i}\right)$. Since the filtration of plasma water makes the concentration of the plasma proteins $\left(C_{p}\right)$ increase, the net oncotic pressure increases down the fibre axis. From the blood inlet to the end of the fibers ( $x=L$, blood outlet) there is a gradual decrease in the effective ultrafiltration pressure. This decrease is due partly to the fall in hydrostatic blood pressure which occurs because of the resistance to flow through the capillary fibers, and partly to the rise in oncotic pressure. Dialysis fluid flows in the opposite direction to the blood flow. Due to flow resistance in the dialysate compartment the pressure rises with the axial position $(x)$ and it is a negative contribution in equation (2). The axial pressure gradient in the dialysate is generally much less than in blood and may be neglected.

In CAVHD, the ultrafiltration volume flux $\left(V_{v}\right)$ is moderate. It is controlled by membrane hydraulic permeability $\left(L_{p}\right)$ and local transmembrane (or ultrafiltration) pressure as given by equation (2). Colton et al. ${ }^{10}$ have demonstrated that at low transmembrane pressure differences (up to $200 \mathrm{mmHg}$ ), the ultrafiltration volume flux $\left(J_{v}\right)$ is proportional to the transmembrane pressure difference and to the membrane hydraulic permeability $\left(L_{\mathrm{p}}\right)$, while, at high transmembrane pressures, the ultrafiltration volume flux reaches a limit. Since in CAVHD, the observed transmembrane pressure difference is up to $80 \mathrm{mmHg}$, we can assume that the ultrafiltration volume flux may be given by

$J_{v}=\alpha+\beta x$,

where the variable $(x)$ represents the longitudinal distance along the hemofilter length, and $\alpha$ and $\beta$ are constants and given (see Table 1) by:

$$
\begin{aligned}
\alpha=L_{\mathrm{p}}\left(P_{\mathrm{bi}}\right. & \left.-P_{\mathrm{r}}-P_{\text {maci }}\right), \beta \\
& =-\frac{L_{\mathrm{p}}}{L}\left(P_{\mathrm{bi}}-P_{\mathrm{bo}}-P_{\text {onci }}+P_{\text {onco }}\right) .
\end{aligned}
$$

The continuity on the both side of the membrane over a differential length $(\mathrm{d} x)$ may be expressed in the differential form:

$$
\frac{\mathrm{d} Q_{w}}{\mathrm{~d} x}=-\frac{\mathrm{d} Q_{\mathrm{d}}}{\mathrm{d} x}=-w /
$$

where $Q_{w}$ and $Q_{v}$ are local flow rates of plasma water and dialysate respectively and $w$ is the ratio of total membranc surface area $(S)$ to the fibre length $(L)$, which corresponds to the width of the hemofilter. On integrating equation (9) from 0 to $x$ using equation (7), we find the local plasma water flow rate:

$Q_{w}=Q_{\mathrm{wi}}-w\left(\alpha x+\frac{1}{2} \beta x^{2}\right)$,

in which the second term on the right hand side equals the cumulative rate of ultrafiltrate flow $\left(Q_{f}(0, x)\right)$ along the filter from the blood inlet $(x=0)$ to a point $x$. Consequently the equation for dialysate flow rate $\left(Q_{1}\right)$ is:

$Q_{d}=w\left(\alpha x+\frac{1}{2} \beta x^{2}\right)-Q_{\text {sco }}$. 
The total ultrafiltration rate $\left(Q_{f}\right)$ is the value of the cumulative flow rate at $x=L$, which follows from integrating equation (9):

$$
Q_{\mathrm{f}}=Q_{\mathrm{vi}}-Q_{\mathrm{vi}}=Q_{\mathrm{s}, \mathrm{i}}-Q_{\mathrm{di}}=S L_{\mathrm{p}} T M P
$$

with $T M P$, the mean transmembrane pressure difference:

$$
T M P=\frac{1}{2}\left(P_{\mathrm{bi}}+P_{\mathrm{bx},}-P_{\text {onci }}-P_{\text {sonco }}\right)-P_{\mathrm{c}} \text {. }
$$

The hydraulic permeability $L_{\mathrm{p}}$, expressing the ultrafiltration coefficient per unit of membrane surface area, can be calculated from equation (12).

\section{Solute mass balance}

The mass balance for a particular solute over a differential length $(\mathrm{d} x)$ of the hemofilter implies that the mass removal from the blood compartment is equal to the mass gain into the dialysate compartment:

$\frac{\mathrm{d}\left(Q_{\mathrm{w}} C_{\mathrm{w}}\right)}{\mathrm{d} x}=-\frac{\mathrm{d}\left(Q_{\mathrm{s}} C_{\mathrm{d}}\right)}{\mathrm{d} x}=-w J_{\mathrm{s}}$

Using equations (7) and (9), we substitute equation (6) in equation (14) and get:

$Q_{\mathrm{u}} \frac{\mathrm{d} C_{\mathrm{w}}}{\mathrm{d} x}=w\left(\frac{J_{v}}{2}-K_{\mathrm{c}}\right) \Delta C$

$Q_{\mathrm{s}} \frac{\mathrm{d} C_{\mathrm{d}}}{\mathrm{d} x}=u\left(\frac{J_{v}}{2}+K_{\mathrm{c}}\right) \Delta C$.

Equations (15) and (16) can be solved analytically for $C_{\mathrm{w}}$ and $C_{\mathrm{d}}$, using equations (7)-(12). Integrating the sum of equations (15) and (16) over a distance from 0 to $x$, we obtain the overall mass balance:

$\int_{11}^{x} \frac{\mathrm{d}}{\mathrm{d} y}\left(Q_{w} C_{w}+Q_{\mathrm{H}} C_{41}\right) \mathrm{d} y=0$.

where $y$ is a dummy variable. Consequently:

$Q_{\mathrm{w}} C_{\mathrm{w}}+Q_{\mathrm{si}} C_{d}=Q_{\mathrm{wi}} C_{\mathrm{wi}}-Q_{\mathrm{si}} C_{\mathrm{do}} \equiv \Delta M$,

which means that the solute mass transport rate from the blood compartment into the dialysate compartment is the same everywhere along the filter length and equals $\Delta \mathrm{M}$.

\section{Concentration profiles}

On integrating the difference $\left(\mathrm{d} C_{\mathrm{w}} / \mathrm{d} x-\mathrm{d} C_{\mathrm{d}} / \mathrm{d} x\right)$ from equations (15)-(16) over a differential length $(\mathrm{d} x)$ of the hemofilter we obtain:

$C_{\mathrm{w}}-C_{\mathrm{cl}}=\left(C_{\mathrm{wij}}-C_{\mathrm{d} \mathrm{d}}\right) e^{I+K_{\mathrm{d}}\left(I_{1}-l_{2}\right)}$,

where $C_{\mathrm{si}}\left(C_{\mathrm{ten}}\right)$ is blood (dialysate) inlet (outlet) solute concentration and variables $I, I_{1}$ and $I_{2}$ represent:

$$
\begin{aligned}
& I=\frac{1}{2} \ln \left(\frac{Q_{\mathrm{wi}} Q_{\mathrm{d} v}}{Q_{\mathrm{w}}\left(-Q_{\mathrm{i}}\right)}\right) \\
& I_{1}=\int_{0}^{x} \frac{\mathrm{d} y}{-\frac{1}{2} \beta y^{2}+\alpha y-} \overline{Q_{\mathrm{wi}} / w}
\end{aligned}
$$

$I_{2}=\int_{0}^{x} \frac{\mathrm{d} y}{-\frac{1}{2} \beta y^{2}+\alpha y-Q_{\mathrm{H} o} / w}$.

Defining the discriminant $q_{k}$ :

$q_{k}=\alpha^{2}+2 \beta Q_{k} / u$,

where if $k=1, q_{\mathrm{k}}=q_{1}, Q_{\mathrm{k}}=Q_{\mathrm{wi}}$ yielding $I_{1}$ and if $k=2, q_{\mathrm{k}}=q_{2}, Q_{k}=Q_{\mathrm{lo}}$ yielding $I_{2}$. The solutions to equations (21)-(22) are to be found in standard reference books ${ }^{11}$ :

for $q_{\mathrm{k}}>0$ :

$I_{\mathrm{h}}=\frac{\ln \left|\frac{\beta x+\alpha-\sqrt{q_{k}}}{\beta x+\alpha+\sqrt{q_{\mathrm{k}}}}-\ln \right| \frac{\alpha-\sqrt{q_{\mathrm{k}}}}{\alpha+\sqrt{q_{\mathrm{k}}}} \mid}{\sqrt{q_{\mathrm{k}}}} \mid$

for $q_{\mathrm{k}}<0$ :

$I_{\mathrm{k}}=\frac{\arctan \left(\frac{\beta x+\alpha}{\sqrt{-q_{k}}}\right)-\arctan \left(\frac{\alpha}{\sqrt{-q_{k}}}\right)}{\frac{\sqrt{-q_{k}}}{2}}$

for $q_{\mathrm{k}}=0$ :

$I_{k}=\frac{2}{\alpha}\left(1-\frac{\alpha}{\alpha+\beta x}\right)$.

Multiplication of equation (19) by $Q_{\mathrm{w}}$ and subtraction of the resulting expression from equation (18) yields:

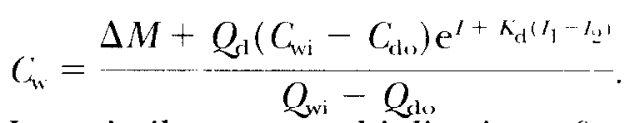

In a similar way, multiplication of equation (19) by $Q_{1}$ and addition of the resulting expression to equation (18) yields:

$C_{\mathrm{d}}=\frac{\Delta M-Q_{\mathrm{w}}\left(C_{\mathrm{wi}}-C_{\mathrm{de},}\right) \mathrm{e}^{I+K_{\mathrm{d}}\left(I_{1} I_{w}\right)}}{Q_{\mathrm{wi}}-Q_{\mathrm{tw}}}$

In order to solve the concentration equations (27)-(28), one needs to know the mass transfer coefficient $\left(K_{\mathrm{t}}\right)$.

\section{Clearance and overall mass transfer coefficient}

In clinical hemodialysis, the ratio of the rate of solute mass removal to its concentration at the blood inlet is called clearance $(C l)$. It is calculated from the macroscopic (overall) mass balance cquations and measured mostly from the dialysate side:

$C l=Q_{\mathrm{so}} \frac{C_{\mathrm{d}, 0}}{C_{\mathrm{wi}}}=C l_{\mathrm{D}, 1}+C l_{\mathrm{c}, 1}$,

with the assumption that solute concentration at the dialysate inlet $\left(C_{\mathrm{di}}\right)$ is zero. Measured clearance $(C l)$ can be seen as the sum of diffusive clearance $\left(C l_{D, 1}\right)$ when the ultrafiltration is zero and the convective clearance $\left(C k_{i, 1}\right)$ when the dialysate flow is zero ${ }^{12}$. In conventional hemodialysis, since the convective component $C_{c, 1}$ is practically zero, 
the overall mass transfer coefficient $\left(K_{o}\right)$ is determined from $\mathrm{Cl} \approx \mathrm{Cl}_{\mathrm{D}, 1}{ }^{6}$ :

$K_{o}=\frac{Q_{\mathrm{wi}} Q_{\mathrm{di}}}{S\left(Q_{\mathrm{vi}}-Q_{\mathrm{di}}\right)} \ln \left[\left(\frac{C l_{\mathrm{D}, 1}-Q_{\mathrm{wi}}}{C l_{\mathrm{D}, 1}-Q_{\mathrm{di}}}\right)\left(\frac{Q_{\mathrm{di}}}{Q_{\mathrm{wi}}}\right)\right]$.

$C l_{\mathrm{D}, 1}$ and $C l_{\mathrm{C}, 1}$ in equation (29) are not rigorously defined in terms of true diffusive and convective clearances. For $J_{v}=0$ and consequently for $Q_{f}=$ $0, C l_{D, 1}$ represents pure diffusive clearance. However, we are interested in CAVHD where the volume flux $\left(J_{v}\right)$ decreases along the membrane length as given by equation (7). This means that the condition of zero net ultrafiltration $Q_{f}=0$ is not necessarily combined with the condition of $J_{v}$ $=0$, but with the case of $J_{\mathrm{v}}>0$ in the first half and $J_{v}<0$ in the second half (backfiltration) of the hemofilter. In order to define the true convective and diffusive clearance, the measured clearance from equation (29) can be separated into convective $\left(C l_{\mathrm{C}, 2}\right)$ and diffusive $\left(C l_{\mathrm{D}, 2}\right)$ components ${ }^{7}$ :

$$
\begin{aligned}
& C l_{\mathrm{C}, 2}=\frac{S}{2 L C_{\mathrm{wi}}} \int_{0}^{L} J_{\mathrm{v}}\left(C_{\mathrm{w}}+C_{\mathrm{d}}\right) \mathrm{d} x \\
& C l_{\mathrm{D}, 2}=\frac{S K_{\mathrm{d}}}{L C_{\mathrm{wi}}} \int_{0}^{L}\left(C_{\mathrm{w}}-C_{\mathrm{d}}\right) \mathrm{d} x .
\end{aligned}
$$

In order to determine the mass transfer coefficient $K_{d}$ in equation (32), we solve equation (19) for $K_{\mathrm{d}}$ at the boundary condition $(x=L)$ and write it in terms of $K_{\mathrm{o}}$ :

$$
K_{\mathrm{d}}=\frac{S K_{o}\left(\frac{Q_{\mathrm{wi}}-Q_{\mathrm{di}}}{Q_{\mathrm{di}} Q_{\mathrm{wi}}}\right)+\frac{1}{2} \ln \left(\frac{Q_{\mathrm{wo}} Q_{\mathrm{di}}}{Q_{\mathrm{wi}} Q_{\mathrm{do}}}\right)}{I_{1}(L)-I_{2}(L)}
$$

in which $I_{1}(L)$ and $I_{2}(L)$ are calculated by equations (21)-(22) at $x=L$. For $J_{\mathrm{v}}=0, K_{\mathrm{d}} K_{\mathrm{o}}=1$. The term $S K_{\mathrm{o}}[\mathrm{ml} / \mathrm{min}]$ in equation (33) is the diffusive permeation coefficient at zero ultrafiltration ${ }^{13}$.

In most clinical applications, however, the ultrafiltration volume flux is assumed to be constant along the hemofilter length and calculated from the net rate of ultrafiltration flow:

$J_{\mathrm{a}}=Q_{\mathrm{f}} / S$.

With $J_{a}$ as given by equation (34), the flow profiles from equations (10)-(11) become: $Q_{\mathrm{v}}(x)=Q_{\mathrm{vi}}-w J_{\mathrm{a}} x$ and $Q_{\mathrm{d}}(x)=w J_{\mathrm{a}} x-Q_{\mathrm{do}}$. Consequently, the term $\left\{I_{1}(L)-I_{2}(L)\right\}$ in equation (33) becomes:

$I_{1}(L)-I_{2}(L)=\frac{S}{Q_{f}} \ln \left(\frac{Q_{\mathrm{wo}} Q_{\mathrm{do}}}{Q_{\mathrm{wi}} Q_{\mathrm{di}}}\right)$.

On substitution of equation (35) in equation (33), one obtains the diffusive mass transfer coefficient $K_{\mathrm{a}}$ for constant volume flux $J_{\mathrm{a}}$ :

$$
K_{\mathrm{a}}=\frac{K_{o} Q_{f}\left(\frac{Q_{\mathrm{wi}}-Q_{\mathrm{di}}}{Q_{\mathrm{di}} Q_{\mathrm{wi}}}\right)+\frac{Q_{\mathrm{f}}}{2 S} \ln \left(\frac{Q_{\mathrm{wo}} Q_{\mathrm{di}}}{Q_{\mathrm{wi}} Q_{\mathrm{do}}}\right)}{\ln \left(\frac{Q_{\mathrm{wo}} Q_{\mathrm{do}}}{Q_{\mathrm{wi}} Q_{\mathrm{di}}}\right)} .
$$

Equation (30) is valid for $J_{v}=0$. Equation (36) is valid for $J_{\mathrm{v}}=J_{\mathrm{a}}=Q_{\mathrm{f}} / S$ and cquation (33) is valid for $J_{v}=\alpha+\beta x$.

\section{EXPERIMENTAL EVALUATION OF THE MODEL}

To evaluate the mathematical model equations (30), (33) and (36), data were used from clinical measurements. Patients were treated with CAVDH for acute renal failure using the AN-69 $0.6 \mathrm{~m}^{2}$ capillary dialyser (Multiflow 60, Hospal, France). Pre- and postfilter hydrostatic blood pressures $\left(P_{\mathrm{bi}}\right.$ and $\left.P_{\mathrm{bo}}\right)$ were measured in the arterial and venous tubing, and dialysate pressure $\left(P_{\mathrm{d}}\right)$ was calculated from the ultrafiltrate column height $(0.74 \times$ column height in centimeters). Arterial blood flow rate $\left(Q_{b}\right)$ was measured by following the displacement of an air bubble over a length of tubing, containing a volume of $13 \mathrm{ml}$. Dialysate rate $\left(Q_{\mathrm{di}}\right)$ and infusion rate of the substitution fluid $\left(Q_{\text {pred }}\right)$ 'pre-dilution' were determined by means of an electronic weighing device. Net ultrafiltration rate $\left(Q_{f}\right)$ was determined by timed collection. Arterial hematocrit $(H t)$ and arterial plasma protein concentration $\left(C_{\mathrm{p}}\right)$ and arterial solute concentration in plasma $\left(C_{\mathrm{pl}}\right)$ were measured. The inlet $\left(C_{\mathrm{pi}}\right)$ and outlet $\left(C_{\mathrm{po}}\right)$ plasma protein concentrations were calculated from the protein mass balance as given by Pallone $e t$ al. :

$$
\begin{aligned}
C_{\mathrm{pi}} & =\frac{C_{\mathrm{p}} Q_{\mathrm{b}}(1-H t)}{Q_{\mathrm{b}}(1-H t)+Q_{\mathrm{pred}}} \\
C_{\mathrm{po}} & =\frac{C_{\mathrm{p}} Q_{\mathrm{b}}(1-H t)}{Q_{\mathrm{b}}(1-H t)+Q_{\mathrm{pred}}-Q_{f}} .
\end{aligned}
$$

The pre- $\left(P_{\text {onci }}\right)$ and postfilter $\left(P_{\text {onci }}\right)$ oncotic pressures were calculated according to the Landis-Pappenheimer formula ${ }^{14}$ by a third order polynomial from the inlet and outlet plasma protein concentrations:

$$
\begin{aligned}
P_{\text {onci }} & =2.1 C_{\mathrm{pi}}+0.16 C_{\mathrm{pi}}^{2}+0.009 C_{\mathrm{pi}}^{\mathrm{g}} \\
P_{\text {onco }} & =2.1 C_{\mathrm{po}}+0.16 C_{\mathrm{po}}^{2}+0.009 C_{\mathrm{po}}^{\mathrm{g}} .
\end{aligned}
$$

The flow rate of plasma water $\left(Q_{\mathrm{wi}}\right)$ and the solute concentration in plasma water $\left(C_{\mathrm{wi}}\right)$ at the filter inlet were calculated by:

$$
\begin{aligned}
Q_{\mathrm{wi}} & =Q_{\mathrm{b}}(1-H t)\left(1-\sigma C_{\mathrm{p}}\right)+f H t Q_{\mathrm{p}}+Q_{\mathrm{pred}} \\
C_{\mathrm{wi}} & =\frac{C_{\mathrm{pl}}}{1-\sigma C_{\mathrm{pi}}},
\end{aligned}
$$

where $f$ is the fractional volume distribution of solute in blood cells. We take $f=0.8^{15}$ for urea and $f=0$ for creatinine, $\sigma=0.00107$. At the dialysate inlet, the dialysate flow rate $\left(Q_{\mathrm{di}}\right)$ was set at different values, namely $1,0.5,2$ and $31 / h$. The equilibration solute concentration was measured in the mixture of ultrafiltrate plus spent dialysate $\left(C_{\mathrm{do}}\right)$.

\section{RESULTS}

The model equations have been evaluated for clinical data of urea clearance. Within the limits 
Table 2 The ranges of measured values during clinical measuring of urea clearance. Filter length $L=0.13 \mathrm{~m}$, total surface area $S=$ $0.6 \mathrm{~m}^{2}$ are manufacture specifications

\begin{tabular}{|c|c|c|c|}
\hline Variables & Range of values & Variables & Range of values \\
\hline$Q_{,},[\mathrm{ml} / \mathrm{min}]$ & $80-345$ & $P_{\mathrm{hi}}[\mathrm{mmHg}]$ & $37-88$ \\
\hline$Q_{\mathrm{di}}[\mathrm{ml} / \mathrm{min}]$ & $7-56$ & $P_{\mathrm{b} w}[\mathrm{mmHg}]$ & $12-42$ \\
\hline$Q_{J}[\mathrm{ml} / \mathrm{min}]$ & $3-18$ & $P_{\mathrm{a}}[\mathrm{mmHg}]$ & $(-65)-(-1)$ \\
\hline$U_{\mathrm{prcd}}[\mathrm{ml} / \mathrm{min}]$ & $(1-17$ & $H t$ & $0.18-0.38$ \\
\hline$C_{p}[\mathrm{~g} / \mathrm{l}]$ & $37-85$ & $C_{\mathrm{dol}}[\mathrm{mmol} / \mathrm{l}]$ & $6-39$ \\
\hline$C_{p \mathrm{i}}[\mathrm{mmol} / \mathrm{l}]$ & $9-40$ & $\left.C_{\mathrm{ali}} / \mathrm{mmol} / \mathrm{l}\right]$ & () \\
\hline
\end{tabular}

of operating conditions by CAVHD (see Table 2), urea clearance was measured with the same type of hemofilters (Multiflow AN-69 Hospal with $S=$ $0.6 \mathrm{~m}^{2}$ and $L=0.13 \mathrm{~m}$ ). For each measurement, the diffusive and convective urea clearance, the hydraulic permeability and the mass transfer coefficients (or the overall permeation coefficients) were calculated. In Table 3, the results of urea clearance measurements and calculations are shown for two different filtration fractions $\left(Q_{f} / Q_{w i}\right)$. The calculated diffusive $\left(C l_{1,1}\right.$ and $\left.C \zeta_{\mathrm{D}, 2}\right)$ and convective components $\left(C l_{C, 1}\right.$ and $\left.C l_{C, 2}\right)$ are slightly different. The diffusive clearance increases with increasing dialysate flow while the convective component decreases slightly. In Figure 2 , the influence of dialysate flow rate on the urea concentration profiles is shown for $Q_{\mathrm{di}}=7.3,18$, 35.5 and $51 \mathrm{ml} / \mathrm{min}$ at $Q_{f}=18 \mathrm{ml} / \mathrm{min}$ and $Q_{w i}$ $=250 \mathrm{ml} / \mathrm{min}$. At higher rates of dialysate flow, the concentration profiles are like those in the conventional hemodialysis where the overall diffusive permeation coefficient reaches its limit (maximal) value. With increasing dialysate flow, the dialysate concentration will be better distributed over the whole membrane surface area and the dialysate resistance to diffusive mass transfer will be smaller. As a result of this, as can be seen from Table 3, the overall permeation coefficients $\left(S K_{\mathrm{d}}, S K_{\mathrm{a}}\right.$ and $S K_{\mathrm{o}}$ ) increase with increasing rate of dialysate flow, but this increase is different at different rates of the ultrafiltration flow at that time. In order to demonstrate the influence of ultrafiltration flow on the overall permeation coefficient $S K_{\mathrm{d}}$, the ratio $K_{0} / K_{\mathrm{d}}$ as well as the ratio $K_{\mathrm{i}} / K_{\mathrm{d}}$ are illustrated in Figure 3 in relation to

Table 3 Urea clearance for two different sets of measurements. The flow rates, clearance and overall permeation coefficients ( $S K_{t}, S K_{t}^{\prime}, S K_{r}$ ) are in units of $\mathrm{ml} / \mathrm{min}$. The overall permeation coefficient represents the diffusion performance capacity of the hemofilter. Convective ( $C l_{k}$ and $\left.C_{\ell_{2}}\right)$ and diffusive $\left(C_{13.1}\right.$ and $\left.C_{4, .2}\right)$ clearance are calculated from measured urea clearance by using equations (29), (31) and (32)

\begin{tabular}{|c|c|c|c|c|c|c|c|c|c|}
\hline$Q_{11}$ & $\theta_{i l \mathrm{o}} / C_{w i}$ & (.l & $C_{1,1}$ & $\left(c_{\vdots, 1}\right.$ & $(\% 10$ & $\left(l_{1,2}\right.$ & $S K_{\gamma 1}$ & $s K_{i}$ & Sh. \\
\hline \multicolumn{10}{|c|}{ (a) $Q_{w i}=81.5 \mathrm{ml} / \mathrm{min}, Q_{\mathrm{r}}=6.5 \mathrm{ml} / \mathrm{min}, T M P=52.6 \mathrm{mmHg}, I_{\mu}=0.2 \mu \mathrm{m} /(\mathrm{min} \cdot \mathrm{mml} / \mathrm{g})$} \\
\hline 8.8 & 0.81 & 11.9 & 6.9 & 5.1 & 7.0 & 4.4 & 15.2 & 15.5 & 14.1 \\
\hline 18.0 & 0.70 & 17.2 & 12.6 & 4.6 & 12.7 & 4.5 & 24.5 & 24.8 & 24.0 \\
\hline 35.6 & 0.57 & 24.2 & 20.5 & 3.7 & 20.2 & .1 .9 & 35.1 & 35.3 & 35.7 \\
\hline 53.0 & 0.51 & 30.5 & 27.1 & 3.3 & 26.7 & 3.7 & 46.1 & 46.3 & 47.2 \\
\hline \multicolumn{10}{|c|}{ (b) $Q_{\mathrm{wi}}=250.4 \mathrm{ml} / \mathrm{min}, Q=18.0 \mathrm{ml} / \mathrm{min}, T M P=78.4 \mathrm{mmHg}, I_{1},=0.38 \mu \mathrm{m} /(\mathrm{min} \cdot \mathrm{mmHg})$} \\
\hline 7.3 & 0.93 & 23.6 & 6.8 & 16.8 & 7.8 & 1.5 .8 & 29.1 & 31.0 & 20.0 \\
\hline 18.0 & 0.92 & 33.1 & 16.6 & 16.6 & 17.9 & 15.2 & 58.4 & 60.6 & 47.8 \\
\hline 35.5 & 0.87 & 46.7 & 31.0 & 15.7 & 32.4 & 14.4 & 88.7 & 90.8 & 80.0 \\
\hline 51.0 & 0.80 & 55,4 & 40.9 & 14.4 & 41.9 & 13.4 & 97.7 & 99.5 & 99.5 \\
\hline
\end{tabular}

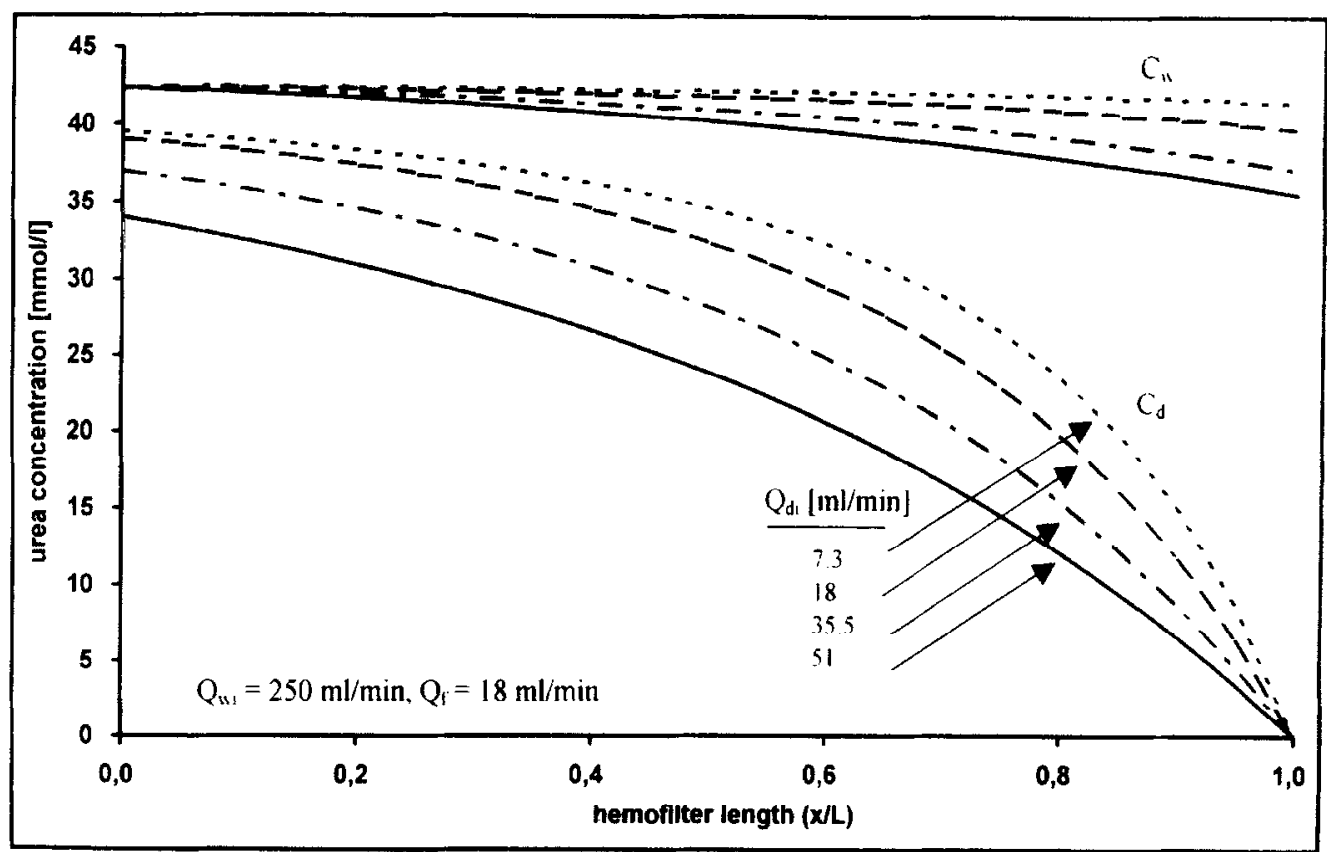

Figure 2 Urea concentration profiles in blood $\left(C_{\mathrm{w}}\right)$ and in dialysate $\left(C_{\mathrm{t}}\right)$ compartment as a function of hemofilter length ( $\left.x / L\right)$ for $Q_{\mathrm{di}}=7.3,18.35 .5$ and $51 \mathrm{ml} / \mathrm{min}$ with $Q_{\mathrm{wi}}=250 \mathrm{ml} / \mathrm{min}$ and $Q=8 \mathrm{ml} / \mathrm{min}$ 


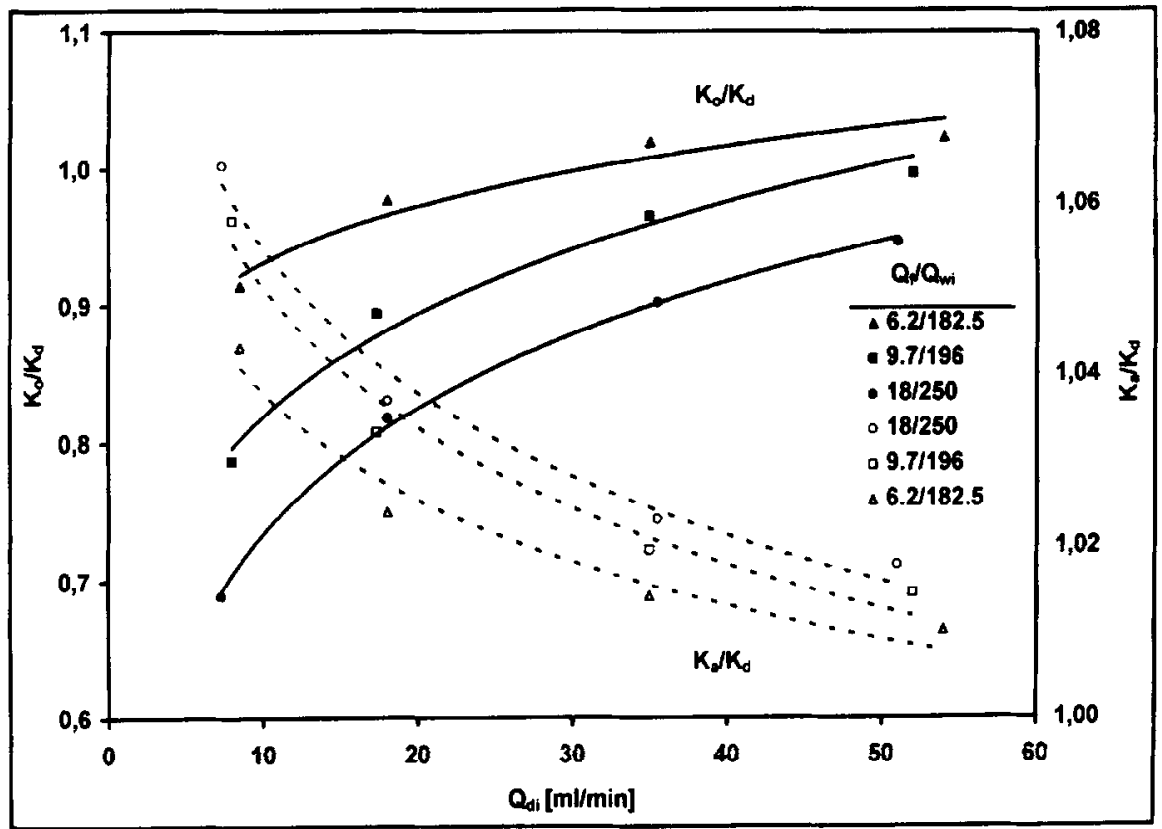

Figure 3 Ratio of the mass transfer coefficient $K_{,}$to the mass transfer coefficient $K_{\mathrm{d}}$ in relation to dialysate flow rate $Q_{\mathrm{di}}$ [ml/min] for the filtration fractions $Q_{f} / Q_{\mathrm{wi}}=6.2 / 182.5,9.7 / 196$ and $18 / 250$. The broken lines show the relation between $K_{\mathrm{a}} / K_{\mathrm{d}}$ and the dialysate flow rate $Q_{\mathrm{fi}}$

dialysate flow rates at three different ultrafiltration flow rates (or filtration fractions). The trend lines show that at high rates of dialysate flow and low rates of ultrafiltration, the ratio $K_{\mathrm{d}} / K_{\mathrm{o}}$ approaches 1 where the value of $K_{\mathrm{d}}=K_{\mathrm{o}}$ is independent of both flow rates and it represents the permeation coefficient of the dialyser in a conventional hemodialysis. At flow rates for $Q_{f} \ll Q_{\mathrm{wi}} \ll$ $Q_{\mathrm{di}}$, the effect of ultrafiltration on the overall permeation coefficient is negligible, as is almost the case in conventional hemodialysis. When the dialysate flow rates are low as compared with the rates of ultrafiltration flow, the effect of ultrafiltration on the overall permeation coefficient becomes significant. In order to show the general trend, the ratio $K_{\mathrm{o}} / K_{\mathrm{d}}$ in relation to the ratio $Q_{f} / Q_{\mathrm{di}}$ is shown in Figure 4 for 67 different cases of the urea clearance measurements.
The ultrafiltration flow reduces the overall mass transfer coefficient due to the reduction of the concentration gradient ${ }^{6}$. At flow rates for $Q_{\mathrm{di}} \ll$ $Q_{\mathrm{f}} \ll Q_{\mathrm{wi}}$, the total mass removal will be dominated by ultrafiltration, especially at the first half of the hemofilter. For the diffusive transport, the second half part of the hemofilter will be important. Lowering the dialysate flow rate rather than ultrafiltration can cause dialysate saturation $\left(C_{\mathrm{do}} / C_{\mathrm{wi}} \rightarrow 1\right)$ or diffusion equilibrium. As can be seen from Figure 4, the big departures from $K_{\mathrm{d}} / K_{\mathrm{o}}$ $=1$ come out at high values of $Q_{f}$ and low values of $Q_{\mathrm{di}}$ where the convection dominates the clearance process. The clearance becomes equal to the ultrafiltration flow $\left(C l=Q_{f}\right.$, only water transport) when conditions $Q_{\mathrm{di}}=0$ and $C_{\mathrm{do}} / C_{\mathrm{wi}}=1$ are satisfied.

In Figure 3, the ratio $K_{\mathrm{a}} / K_{\mathrm{d}}$ is illustrated in

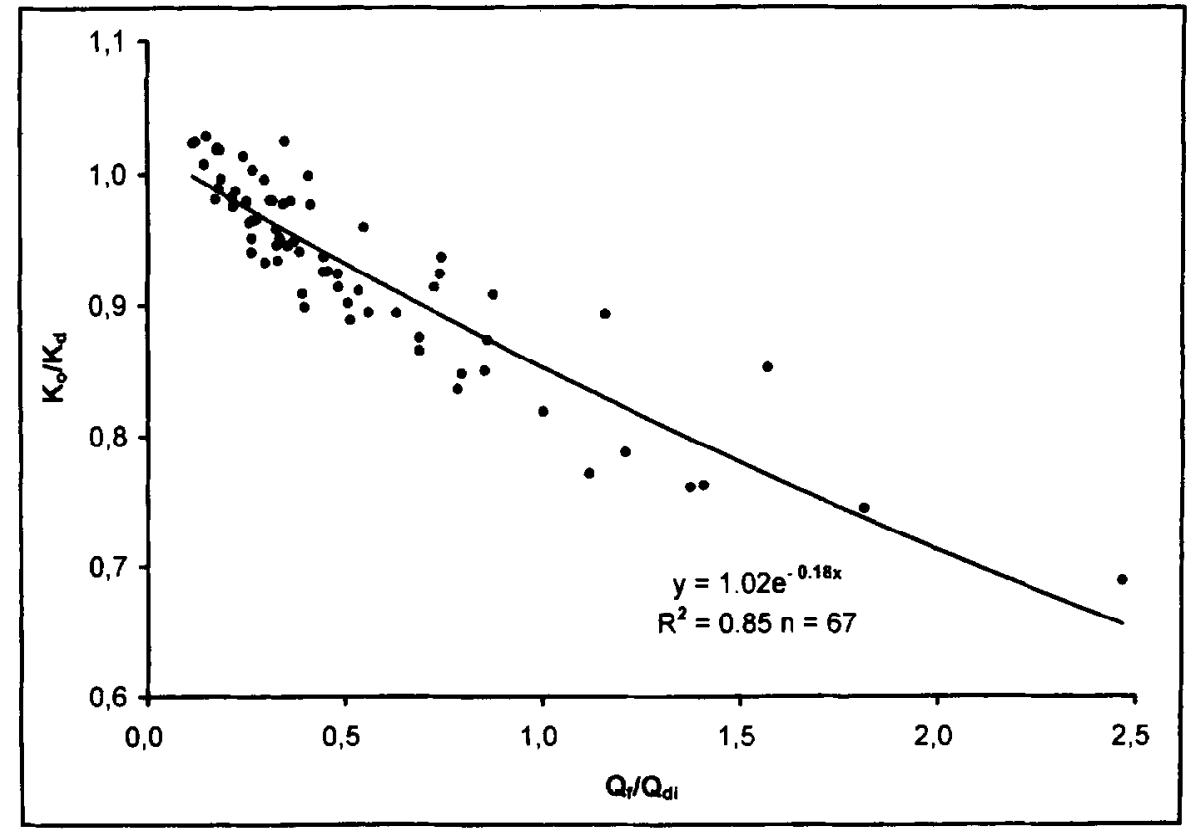

Figure 4 The ratio $K_{o} / K_{d}$ in relation to the ratio of ultrafiltration flow rate to the dialysate flow rate $\left(Q_{J} / Q_{\text {fil }}\right)$ for different filtration fractions. The trend line shows the best fit to the experimental data points: $y=1.02 \mathrm{e}^{-0 . \mathrm{I} 8 x}\left(K^{2}=0.85, n=67\right)$ with $x=Q_{f} / Q_{\mathrm{di}}$ and $y=K_{\mathrm{o}} / K_{\mathrm{d}}$ 
Table 4 Urea clearance was measured with $P_{\mathrm{d}}=-1 \mathrm{mmHg}, P_{\mathrm{bi}}=73 \mathrm{mmHg}, P_{\mathrm{bu}}=25 \mathrm{mmHg}, H \mathrm{t}=0.39, C_{\mathrm{p}}=85 \mathrm{~g} / \mathrm{l}(\mathrm{TW} P=5.9 \mathrm{mmHg})$, $Q_{3}=60 \mathrm{ml} / \mathrm{min}, Q_{\mathrm{d} r+1}=0 \mathrm{ml} / \mathrm{min}\left(Q_{\mathrm{wi}}=52 \mathrm{ml} / \mathrm{min}\right), Q_{\mathrm{j}}=8 \mathrm{ml} / \mathrm{min}\left(Q_{\mathrm{si}}=40 \mathrm{ml} / \mathrm{min}\right), C_{\mathrm{pl}}=32.2 \mathrm{mmol} / 1\left(C_{\mathrm{wi}}=37.6 \mathrm{mmol} / 1\right)$ and $C_{\mathrm{cll}}$, $=12.3 \mathrm{mmol} / 1$. The measured urea clearance is separated into the convective and diffusive components according to the ultrafiltration volume flux models: $J_{v}=0, J_{v}=J_{\alpha}=Q / S$ and $J_{v}=\alpha+\beta x$

\begin{tabular}{|c|c|c|c|c|}
\hline \multirow{2}{*}{$\begin{array}{l}\text { Clearance }[\mathrm{ml} / \mathrm{min}] \text { and } \\
\text { overall permeation } \\
\text { coefficients }[\mathrm{ml} / \mathrm{min}]\end{array}$} & \multirow[t]{2}{*}{ Standard eq. (29) } & \multicolumn{3}{|c|}{ Depending on $/$} \\
\hline & & $J=0$ & $J=J_{S}=Q_{j} S$ & $h=\alpha+\beta x$ \\
\hline ili & 15.7 & 15.7 & 15.7 & 15.7 \\
\hline$C_{1}, 1$ & 13.1 & 0 & - & - \\
\hline$\left(l_{11,3}\right.$ & 2.6 & 15.7 & - & - \\
\hline$\left(2 / x_{2}\right.$ & - & - & t.t & 6.1 \\
\hline$\left(\lambda_{11}, 2\right.$ & $\ldots$ & - & 11.3 & 9.3 \\
\hline$S K$ & - & 18.4 & - & - \\
\hline$S K_{1}$ & - & - & 15.2 & - \\
\hline$S K_{r 1}$ & - & - & - & 10.4 \\
\hline
\end{tabular}

relation to dialysate flow rates. The differences between the values of $K_{\mathrm{a}}$ and $K_{\mathrm{d}}$ at different dialysate and ultrafiltration flow rates are relatively small. However, one important condition of using the constant volume flux model $\left(J_{\mathrm{a}}=Q_{\mathrm{f}} / S\right)$ is that within the hemofilter there is no backfiltration from dialysate into the blood compartment. If the transmembrane pressure gradient becomes negative somewhere in the hemofilter, the assumption of constant volume flux is not valid any more. Using the data from Table 4, the urea flux profiles are shown in Figure 5 for a constant ultrafiltration volume flux $\left(j_{v}=J_{\mathrm{a}}=Q_{\mathrm{f}} / S\right)$ and for a linear decreasing ultrafiltration volume flux $J_{v}=\alpha+\beta x$. The corresponding cumulative values of the same urea clearance are shown in Figure 6. According to the linear decreasing volume flux model, the transmembrane pressure difference is zero at about $x / L=0.58$ where $\left(J_{v}=0\right.$ and $\left.K_{\mathrm{d}}=K_{v}\right)$ the diffusive flux $\left(K_{\mathrm{l}} \Delta C\right)$ and cumulative convective clearance reach their maximal values. From $x / L$ $>0.58$ to $X / L=1$ where $J_{v}<0$, the diffusive flux and cumulative convective clearance decrease with length as a result of backwards convective flux. According to the urea flux profiles $\left(J_{\mathrm{a}} C_{\mathrm{m}}\right.$ and $K_{\mathrm{a}} \Delta C$, shown by broken lines) of the constant volume flux model, the effect of backfiltration on the diffusive urea flux will not be observed. The backwards dialysate fluid (volume flux) reduces the concentration gradient from blood into the dialysate side, resulting in a reduced overall permeation coefficient (see Table 4).

\section{DISCUSSION AND CONCLUSION}

Considering some simplifying conditions, the mathematical analysis shows that the diffusive mass transfer coefficient $K_{\mathrm{d}}$ can be calculated from the clinical data of CAVHD. The mass transfer coefficient $\left(K_{\mathrm{d}}\right)$ represents the overall (apparent) permeation coefficient or diffusive performance capacity of the hemofilter. Its value depends on the flow rates, ultrafiltration, concentration gradient, membrane permeability, the solute molecular weight, deteriorating conditions such as clotting and other physical conditions such as temperature. The $K_{\mathrm{d}}$ represents the overall mass transfer coefficient of a flowing system,

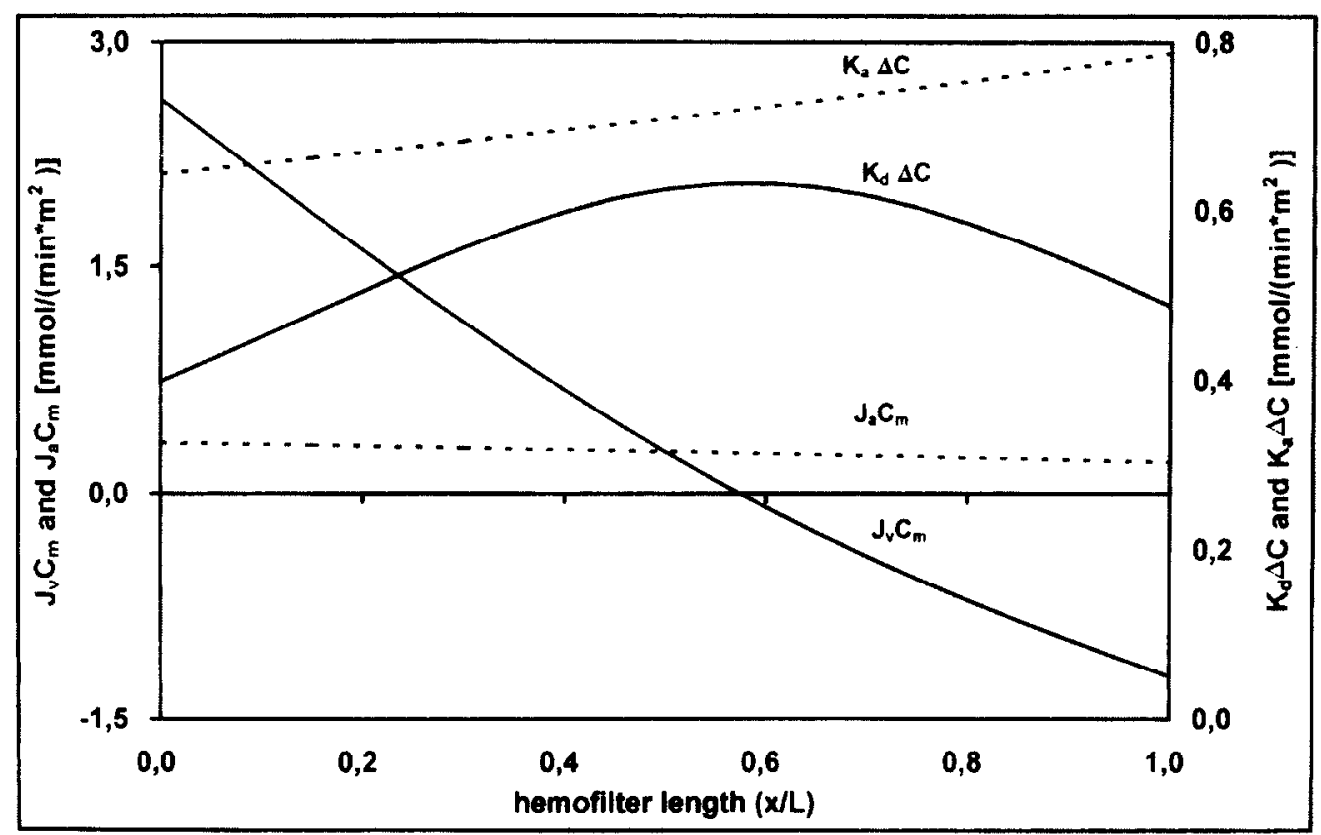

Figure 5 Urea flux profiles as a function of the hemofilter length $(x / L) . L=0.13 \mathrm{~m}$. The urea flux, calculated from the data in Table 3 is separated into convective $\left(J_{v} C_{\mathrm{m}}\right)$ and diffusive $\left(K_{\mathrm{d}} \Delta G\right)$ components by using eq. (6) and eq. (7). Also, the same total urea flux is separated into convective $\left(J_{1} C_{\mathrm{tu}}\right)$ and diffusive $\left(K_{\mathrm{a}} \Delta C\right)$ components (broken lines) by using eq. (6) and eq. (33) 


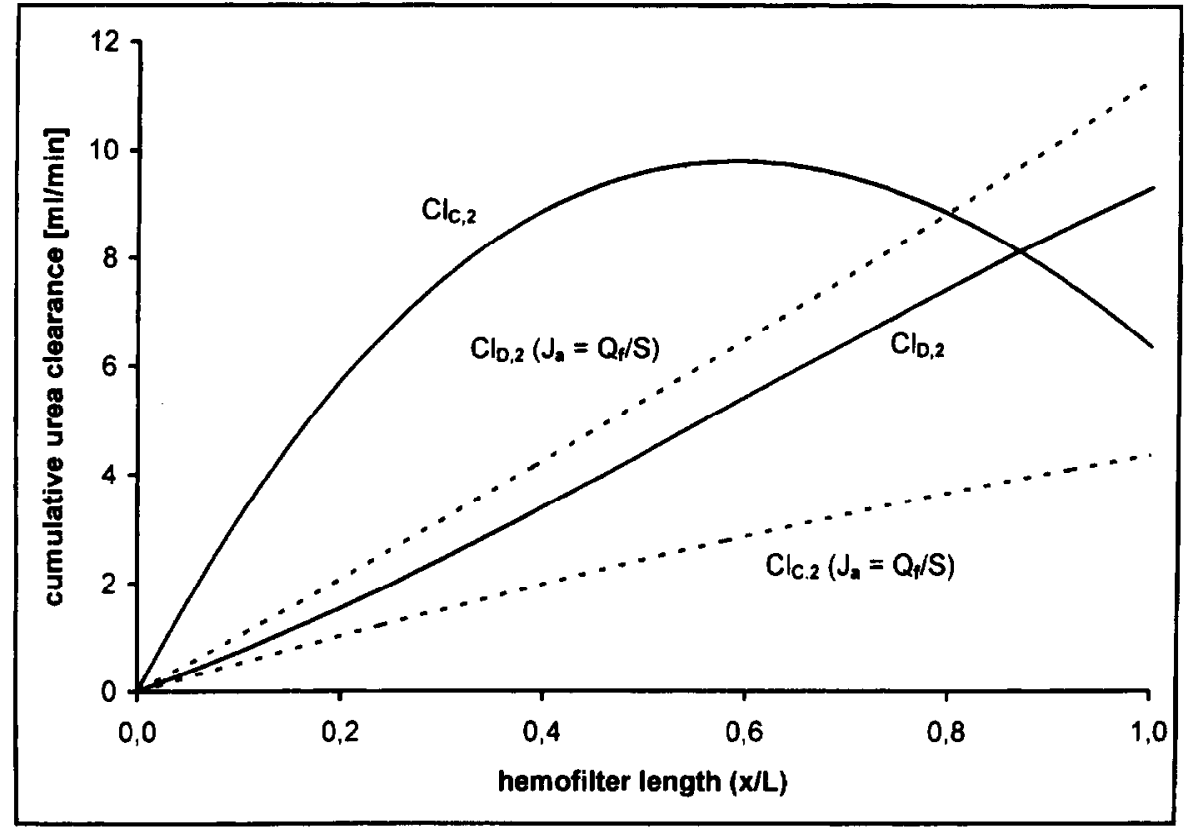

Figure 6 The cumulative urea clearance as a function of the hemofilter length $(x / L)$. The measured urea clearance, calculated from the urea flux profiles in Figure 5 is separated into convective $\left(C l_{C, 2}\right)$ and diffusive $\left(C l_{\mathrm{D}, 2}\right)$ components by using equations (31) and (32). The broken lines show the same components for $J_{v}=J_{\mathrm{a}}=Q_{\mathrm{f}} / S$

from which the lifetime is limited by some unfortunate deteriorating factors.

In conventional intermittent hemodialysis, where the dialysate flow rate is 5 to 6 times larger than that of CAVHD and the ultrafiltration flow is practically zero, the mass transfer coefficient $\left(K_{\mathrm{o}}\right)$, calculated by using equation (30), will not be affected by the dialysate and ultrafiltration flows. When the dialysate flow rates are low as comparable to the ultrafiltration flow rates, the mass transfer coefficient $\left(K_{d}\right)$ of a CAVHD hemofilter has to be determined in the presence of ultrafiltration. By using equation (32), one can calculate the mass transfer coefficient $\left(K_{\mathrm{d}}\right)$ when the ultrafiltration volume flux $\left(J_{v}\right)$ is given by equation (7), namely $J_{\mathrm{v}}=\alpha+\beta x(\beta<0)$. The calculated values of $K_{\mathrm{d}}$ and $K_{\mathrm{o}}$ show that the departure of $K_{\mathrm{o}} / K_{\mathrm{d}}$ from 1 occurs at high values of $Q_{f} / Q_{\mathrm{di}}$ for $Q_{f} / Q_{\mathrm{di}}$ $\ll 1$, the mass transfer coefficient $K_{\mathrm{d}}$ equal to the mass transfer coefficient $K_{\mathrm{o}}$ which is calculated at zero ultrafiltration. Values of the overall permeation coefficient depend not only on the rate of ultrafiltration flow but also on its direction.

Unfortunately, it is not possible to demonstrate the effect of different rates of ultrafiltration flow on the overall permeation coefficient at a constant rate of dialysate flow because the method of ultrafiltrate production in CAVHD differs from that of hemofiltration therapy such as CAVH. In CAVH, the rate of ultrafiltration flow can be adjusted to a certain value while in CAVIID it is limited by spontaneous transmembrane pressure.

For mathematical simplicity, the diffusive mass transfer coefficient can be calculated from equation (35) which is valid for a constant volume flux model $\left(J_{\mathrm{v}}=J_{\mathrm{a}}=Q_{\mathrm{f}} / S\right)$. If conditions are satisfied so that there is no backfiltration in the hemofilter, the use of $K_{\mathrm{a}}$ in place of $K_{\mathrm{d}}$ is preferable. However, assuming a constant volume flux is risky in connection with monitoring the pressure distri- butions along the hemofilter length, because from the clinical point of view, backfiltration needs to be avoided. When the dialysate fluid is filtered back into the blood of the patient, the backfiltration can cause potentially unsterile dialysis fluid or pyrogen to enter the blood of the patient.

This model is based on a linear decreasing volume flux and on solutes with small molecular weight such as urea. A linear decreasing volume flux is not always true especially at very high transmembrane pressure differences. In those cases and for solutes with middle and large molecular weight, the $K_{\mathrm{d}}$ derived from equation (32) can be used as an estimator.

\section{REFERENCES}

1. Vos MC. Continuous Arteriovenous Hemodiafiltration [PhD Thesis] Erasmus University Rotterdam. Uitgeverij Eburn, Delft, 1993.

2. Villarroel F, Klein E, Holland F. Solute flux in hemodialysis and hemofiltration membranes. Trans Am Sor Artif Intern Organs, 1977; 22: 225-33.

3. Zydney LA. Bulk mass transport limitations during highflux hemodialysis. Artif Urgans (1993); 17 (11): 919-24.

4. Jaffrin MJ, Ding L and Laurent JM. Simultaneous convective and diffusive mass transfer in a hemodialyser. $J$ Biomed Eng, 1990; 112: 212-9.

5. Kedem $\mathrm{O}$, Katchalsky A. Thermodynamic analysis of permeability of biological membranes to non-electrolytes. Biochim biophys Acta, 1958; 27: 229-49.

6. Sigdel JE. Calculation of diffusive and convective mass transfer. Int J Artif Organs, 1982; 5: 361-72.

7. Pallone TL, Pettersen J. Continuous arteriovenous hemofiltration: an in vitro simulation and mathematical model. Kidney International, 1988, 33: 685-98.

8 Akcahuseyin E, Vincent $\mathrm{HH}$, van Ittersum FJ, van Duyl WA, Schalekamp MADH. A mathematical model of continuous arterio-venous hemodiafiltration (CAVHD). Computer Methods Prog Biomed 1990; 31: 215-24.

9. Vincent $\mathrm{HH}$, van Ittersum $\mathrm{FJ}$, Akcahuseyin $\mathrm{E}$, Vos $\mathrm{MC}$, van Duyl WA, Schalekamp MAOH. Solute transport in 
continuous arteriovenous hemodiafiltration: a new mathematical model applied to clinical data. Blond Purif, 1990; 8: $149-59$.

10. Colton CK, Henderson CA, Lysaght MJ. Kinetics of hemodiafiltration I-In vitro transport characteristics of a hollow-fibre blood ultrafilter. J Lab Clin Invest 1975; 85: $355-71$.

11. Abramomitz M, Stegun JA (eds) Handbook of Mathematical Functions Dover Publ. Inc, New York, 1965.

12. Sigler MH, Teehan BP, Van Valkenburg D. Solute transport in continuous hemodialysis: a new treatment for acute renal failure. Kidney International, 1987; 32: 562-71.
13. Sargent JA, Gotch FA. Principles and biophysics of dialysis. In: W. Drukker, F.M. Parsons, J.F. Maher, Replacement of Renal Function of Dialysis. Martines Nijhoff Medical Division Publ, The Hague, 1978.

14. Landis EM, Pappenheimer JR. Exchange of substances through the capillary wall, in: Handbook of Physiology, Sect. 2 of Vol. 2, Chapt. 29, pp. 962-1034 (American Physiologic Society, Washington DC, 1963).

15. Colton CK, Smith KA, Merril EW, Reece JM. Diffusion of organic solutes in stagnant plasma and red cell suspensions. Chem Eng Prog Symp (1970) Ser. no:66 Vol:99 pp. $85-100$.

\section{APPENDIX: LIST OF SYMBOLS AND UNITS}

$C_{\mathrm{wm}} \quad$ solute concentration at the blood-mem-

$C_{\mathrm{d}} \quad$ brane interface, $[\mathrm{mmol} / \mathrm{l}]$ in dialysate, [mmol/1]

$\mathrm{Cl}$ solute clearance, $[\mathrm{ml} / \mathrm{min}]$

$C_{c .2}$ convective clearance, equation (31), $[\mathrm{ml} / \mathrm{min}$ ]

$C k_{k, 1} \quad$ convective clearance, equation (29), $[\mathrm{ml} / \mathrm{min}$ ]

$\mathrm{Cl}_{\mathrm{D} .1}$ diffusive clearance, equation (29),

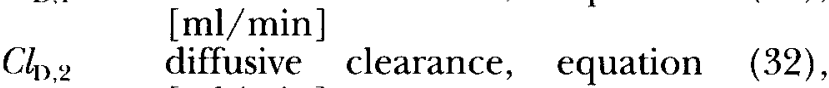
$[\mathrm{ml} / \mathrm{min}]$

$C_{\mathrm{m}} \quad$ effective local solute concentration describing the convective contribution to the total solute transport, [mmol/1]

$C_{\mathrm{md}}$ solute concentration at the membranedialysate interface, $[\mathrm{mmol} / \mathrm{l}]$

$C_{\mathrm{p}} \quad$ arterial concentration of plasma proteins, $[\mathrm{g} / 1]$

$C_{\mathrm{pl}} \quad$ arterial solute concentration in

$C_{\mathrm{w}} \quad$ plasma, [mmol/1] plasma water, $[\mathrm{mmol} / \mathrm{l}]$

$\mathrm{d} x \quad$ differential length, [m]

dy dummy differential length, $[\mathrm{m}]$

$f$ fractional volume distribution of solute in blood cells

$f_{b} \quad$ weighting factor of solute concentration in blood to the convective solute transport

$f_{\mathrm{d}} \quad$ weighting factor of solute concentration in dialysate to the convective solute transport

$\mathrm{Ht}$ arterial hematocrit

$I, I_{1}, I_{2}$ variables defined in equations (20)(22)

$I_{k} \quad$ variables defined in equations (24)(26)

$J_{\text {a }}$ mean (constant) ultrafiltration volume flux, $[\mu \mathrm{m} / \mathrm{min}]$

$J_{\mathrm{s}}$ transmembrane solute flux,

$\left[\mu \mathrm{mol} / \mathrm{min} \cdot \mathrm{m}^{2}\right]$

$J_{v} \quad$ ultrafiltration volume flux, $[\mu \mathrm{m} / \mathrm{min}]$

$k \quad$ index $(k=1$ and $k=2)$

$K_{x} \quad$ overall mass transfer coefficient for a constant $J_{\mathrm{v}}=J_{\mathrm{a}}=Q_{\mathrm{r}} / S,[\mu \mathrm{m} / \mathrm{min}]$

$K_{\mathrm{d}} \quad$ overall mass transfer coefficient for $J_{v}=$ $\alpha+\beta x,\lfloor\mu \mathrm{m} / \mathrm{min}\rfloor$

$K_{1} \quad$ overall mass transfer coefficient for $J_{v}=$ $0,[\mu \mathrm{m} / \mathrm{min}]$
$L$

$I_{\mathrm{p}}$

$N$

$n$

$P_{\mathrm{b}}$

$P_{\mathrm{d}}$

$P_{\mathrm{m}}$

$\mathrm{P}_{\text {one }}$

$Q_{\mathrm{h}}$

$Q_{d}$

$Q_{S}$

$q_{k}$

discriminant defined in equation (23) (23),

( $=Q_{\mathrm{wi}}$ for $k=1$ and $=Q_{\mathrm{do}}$ for $\left.k=2\right)$

$Q_{\text {pred }}$ flow rate of substitution (predilution), $[\mathrm{ml} / \mathrm{min}]$

$Q_{v}$ local flow rate of plasma water, [ml/min]

$r \quad$ internal radius of a fiber, [m]

$R^{2} \quad$ square of the sum of residues

$R_{\mathrm{b}} \quad$ resistance of blood boundary layer to the diffusive mass transport, $[\mathrm{min} / \mu \mathrm{m}]$

$R_{\mathrm{l}} \quad$ resistance of dialysate boundary layer to the diffusive mass transport, $[\mathrm{min} / \mu \mathrm{m}]$

$S \quad$ effective surface area of the hemofilter, $\left[\mathrm{m}^{2}\right]$

$S K_{a} \quad$ overall permeation coefficient for a constant $J_{v}=J_{\mathrm{a}}=Q_{\mathrm{f}} / S,[\mathrm{ml} / \mathrm{min}]$

$S K_{\mathrm{c}} \quad$ overall permeation coefficient for $J_{v}=$ $\alpha+\beta x,[\mathrm{ml} / \mathrm{min}]$

$S K_{v} \quad$ overall permeation coefficient for $J_{v}=$ $0,\lceil\mathrm{ml} / \mathrm{min}\rceil$

TMP mean transmembrane pressure difference, $[\mathrm{mmHg}]$

$w \quad$ width $=S / L=2 N \pi r[\mathrm{~m}]$

$x \quad$ axial position along the hemofilter, $[\mathrm{m}]$

$y \quad$ dummy variable, $[\mathrm{m}]$

Greek letters

$\alpha, \beta \quad$ constants, equation (8)

$\gamma \quad$ sieving coefficient ( $=1$ for urea)

$\Delta C$ concentration gradient $=C_{\mathrm{v}}-C_{\mathrm{d}}$ [mmol/l]

$\Delta M \quad$ difference in solute mass transport rate, equation (18), $[\mathrm{mmol} / \mathrm{min}]$

$\sigma \quad$ protocrit $(=0.00107 \mathrm{l} / \mathrm{g})^{1 \cdot 4}$

Subscripts

i, o inlet, outlet of the hemofilter compartments 